\title{
Editorial
}

\section{COMPLEXITY, RISK AND EMERGENCE: ELEMENTS OF A "MANAGEMENT" DILEMMA}

Risk Management (2006) 8, 221-226. doi:10.1057/palgrave.rm.8250024

\section{Introduction}

lmost by definition, issues of risk are both complex and compli-
cated. The distinction between the two terms is important. There
is little doubt that risk issues are complicated. If they were simple then people would have found effective ways to mitigate the risks. Instead, the cross-cutting relationships between risk and benefit, voluntary and involuntary risk, immediate and delayed effects, probability and consequence all complicate the imbroglio of risks that we face in our daily lives. Indeed, it is this entangled dynamic that makes risk both challenging to manage and an important topic for academic study.

Risk is also complex - especially when viewed from the perspective of modern complexity theory whereby the study of a complex system is seen as being an attempt to assess how "parts of a system give rise to the collective behaviors of the system, and how the system interacts with its environment" (NECSI, 2006). In putting the matter in this way we introduce a further layer of ambiguity to the task of risk management but also bring new insights and understandings. That at least is the motivation behind this special journal issue.

There is a view that the very raison d'être for management resides in the fact that both the process and function of managing are required to deal with uncertainty. If there were no uncertainty within and around organizations, then there would be no need to make decisions and therefore no need for managers. In other words, the principal task of management should be to deal with risk.

Of course, there are many managers and policy makers who would not be in agreement with such a view - and many business schools that only give passing consideration to the processes of risk generation and management (and even then mainly from the perspective of financial risks). Yet the actions and inactions of managers are essential to developing the conditions in which risk is "incubated" (Turner, 1976, 1978), identified, 
contained and (in an ideal world) prevented. Managers ultimately make the decisions that contribute to the pre-cursors of failure and determine the acceptability of residual risk as well as the appropriateness of mitigation strategies.

The relationships between the three main elements of risk (identification, mitigation and reduction) are essential components in any risk management strategy. It is not enough to consider identification, mitigation and reduction as separate processes. Instead, the interactions between them generate conditions that can lead to "risk migration" across the system. In addition, these three pillars of risk management also suffer from a central "fatal flaw" - namely the role of emergence in generating conditions that exceed both the control systems that are in place and the ability of managers to deal with the conditions that "emerge". The manner in which management and regulators respond to this "emergence" creates a new cycle of problems that will, in turn, generate further risks (see, e.g. Giddens, 1990) and there are several examples that illustrate this process. One such example is the case of DDT. The banning of DDT use to eradicate mosquitos was introduced because of concerns over avian eggshell thinning. Ultimately, this led to a re-emergence of malaria in several parts of the world where it had almost been eradicated. Decisions taken for what would appear to be the best reasons can so easily generate consequences that are deemed to be adverse. Herein lies a major dilemma for managers and policy makers - and a central concern for complexity theory. Put simply, how do we deal with the management and mitigation of hazard without facilitating the emergence of new forms of risk further down the timeline?

The aim of this editorial - and of this special issue of Risk Management: An International Journal - is to consider a range of issues around this core problem, and to set out a framework for considering emergence as an element of complexity within the wider process of risk management. It is our contention that the developing literature on complexity has significant implications for the ways in which we conceptualize and manage risk and that this journal has a potentially important role to play in that process.

\section{Complexity and risk: elements of a relationship}

The study of complex systems is about understanding indirect effects. Problems that are difficult to solve are often hard to understand because the causes and effects are not obviously related. Pushing on a complex system "here" often has effects "over there" because the parts are interdependent. This has become more and more apparent in our efforts to solve societal problems or avoid ecological disasters caused by our own actions. (NECSI, 2006)

The description of complex systems research provided by the New England Complex Systems Institute captures some important elements of the process of complexity that have relevance for our present discussions. In particular, 
indirect effects lie at the heart of effective risk analysis and management. Our abilities to identify and "control" the range of indirect effects within a complex socio-technical system have been challenged in the face of numerous catastrophic failures, policy-related hazards, and environmental impacts. The issue of interdependence is also of importance to effective risk management and not only in the ways that have traditionally been considered. Whilst there are clear examples of interdependence and risk generation within technical systems, there has been a growing recognition of the importance of "soft" human issues in creating technically-based failures and, of particular importance, the influence of "management" (as both a function and a process) in shaping failure pathways.

The ability of managers to consider the nature and role of "risk migration" is also an important element in the creation of complex failure pathways. Decisions taken at one point in time may well have serious consequences for the generation of risk elsewhere. This inter-connection of cause and effect in both space and time is an important (but one might argue, neglected) aspect of the so-called "risk society" (Giddens, 1990; Beck, 1992).

\section{Emergence, risk and the limitations of "management"}

Emergent properties within a system are those elements that invariably cause "management" to fail. Most catastrophic failures have occurred because events have exceeded the ability of the organisation to control them. Invariably, the contingency plans put into place to deal with a variety of problems will have been by-passed by events. This will be a result of the emergent properties within the system or the unwillingness of the organisation to consider particular failure pathways as likely events. At the point at which the contingency plans fail to deal with the demands of the event, managers will be forced to make decisions. These decisions may contribute to the processes by which the event escalates to the point at which management loses control (see Figure 1). Throughout this process there will be several points of inflection within the decision making process (Handy, 1995) which will contribute to the generation of risk. As managers take actions to contain the problems that emerge, they will invariably set the failure pathway down a particular route that may generate further emergent triggers. These, in turn, will act as the catalysts for further problems - which may occur over both space and time.

Just to add to this complexity, it should also be noted that management systems do not simply respond to pre-defined risks but must also categorize, identify and construct them within often very dynamic and changeable situations. The old adage suggests that "every problem looks like a nail when one is holding a hammer". In just the same way, one can hypothesize that different management and risk cultures will define threats in rather different ways - and indeed that the sense of threat will help shape management structures (Douglas, 1986). Thus, it is not simply a matter of management responding to 


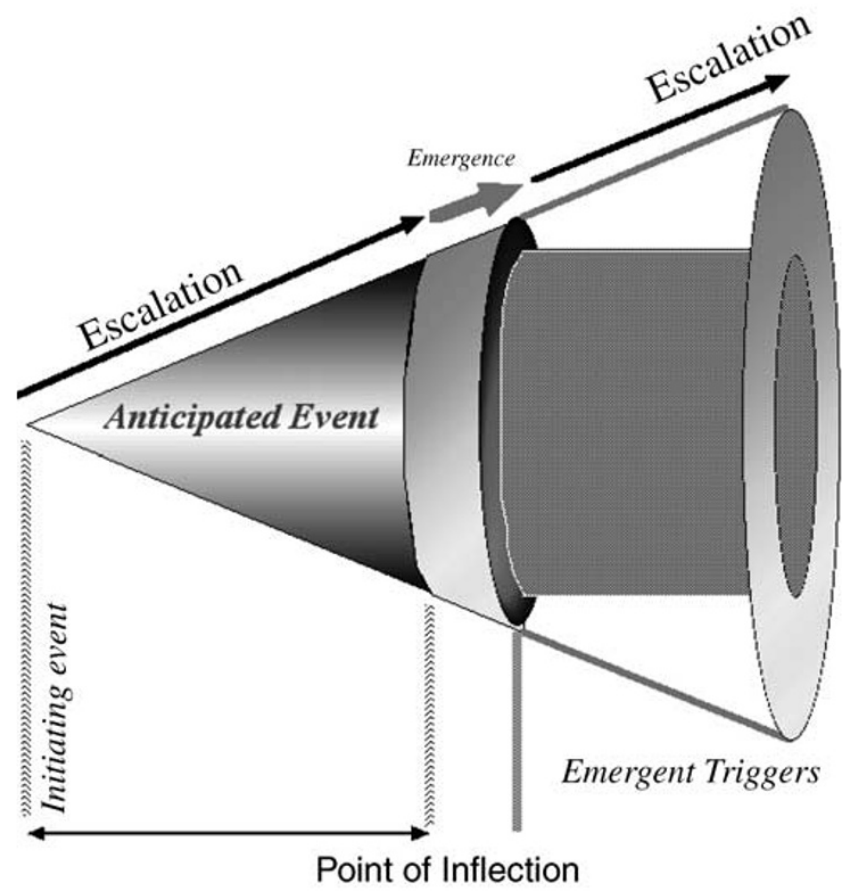

Figure 1 Emergence and the escalation of risk. SOURCE: Smith (2005).

some external threat but also of the manner in which certain risks become prioritized over others and how they are identified and defined. These (often implicit) processes of risk construction will in themselves have unintended and unconsidered consequences across the management process.

It follows from this brief discussion that in dealing with the implications of complex systems, risk management will need to move beyond a linear, cause and effect approach and consider the potential insights that may be afforded by incorporating the complexity literature into the process. For this to be effective, fundamental changes in the approaches taken to educate managers will be necessary. It is here also that the complexity literature can have a significant impact upon the ways in which managers and management educators see the world. By recognizing the limitations of managerial control within complex socio-technical systems, it should be possible to help develop the curriculum of MBA programmes away from the rational-positivistic ("if you can measure it, you can manage it") approach towards a recognition of the processes by which management itself can contribute to the failure process (in terms of allowing the problems to be incubated and prioritizing certain risks over others) as well as to the processes by which the failure escalates. Indeed, from this perspective, attempts at imposing inappropriate quantification on complex and systemic issues can appear - contrary to the usual modernistic belief - to represent a loss 
of control and a contribution to the risk management problem rather than the solution.

\section{In search of debate}

The papers in this edition of the journal seek to examine these processes of risk and complexity. Each of the papers offers a different perspective on the nature of the process. Johnson highlights the broad relationship between complexity and risk and discusses the manner in which the science of complex dynamics can influence core design and management issues within organizations. $\mathrm{He}$ also highlights the importance of the boundary problem issue in understanding how modern organizations fail though their networks of activities. The simulation approaches used within complexity theory may well offer important insights into the generation of risk across as well as within organizations.

Baldwin et al continue to develop the simulation theme as they explore the findings of new theories around evolutionary approaches to organizations and seek to identify mechanisms through which such evolutionary processes contribute to the emergence of risk. The relationship between organisational form and the generation of hazard brings an interesting new perspective to the process of risk management. They also explore the perceptual processes of managers in shaping the generation of hazard across the supply chain - an issue that further reinforces the importance of networks in risk generation and mitigation.

Brookfield and Smith consider the implications that complexity has for risk within healthcare and they set out some issues around the notion of control. Once again, the role of networks is considered in this discussion. On this occasion, it is the informal networks that exist in organizations - especially those where professional affiliation is a powerful mechanism for preventing access to network members. The issue of finance within a health care setting brings many issues to the fore regarding multiple networks of expertise within organizations and the problems that this can generate for management control.

Finally, Allen et al also focus on the evolutionary issue but from the perspective of multi-agent modelling and the impact that networks can have on the generation of resilience within organizations. Allen et al highlight the problems of cause and effect relationships within organizations and the difficulties that traditional methods of analysis have in shaping our understanding of reliance dynamics within complex systems due to the importance of multiple agents in the process. Again, the importance of networks within the development and escalation of risk is highlighted.

Taken as a whole, these papers offer insights into the manner in which organisational networks can be important in shaping risk generation and migration. They also allude to the role that such networks can play in shaping the underlying processes of risk generation. It may be the case that networks offer the opportunity for us to change the social construction of risk in a manner 
that allows for more emphasis on prevention across the range of risk issues facing organizations.

Clearly, the discussion here marks the beginning of a dialogue around the issues of risk and complexity rather than a definitive exposition of the problem. It is our hope that the relationships between the complexity literature and work on risk management will be returned to in subsequent issues of the journal. As such, the emergence generated by such a discussion may generate new insights into research across many areas.

\section{References}

Beck, U. (1992). Risk Society: Towards a New Modernity. London: Sage.

Douglas, M. (1986). How Institutions Think. Syracuse NY: Syracuse University Press.

Giddens, A. (1990). The Consequences of Modernity. Cambridge: Polity Press.

Handy, C. (1995). The Empty Raincoat. London: Arrow Business.

NECSI (2006). About complex systems. New England Complex Systems Institute Accessed at http://www.necsi.org/guide/study.html on the 6th October 2006 (at 1816 hours).

Smith, D. (2005). Dancing Around the Mysterious Forces of Chaos: Exploring Issues of Complexity, Knowledge and the Management of Uncertainty. Clinician in Management 13 (3-4), pp. 115-123.

Turner, B.A. (1976). The Organizational and Interorganizational Development of Disasters. Administrative Science Quarterly 21, 378-397.

Turner, B.A. (1978). Man-made Disasters. London: Wykeham.

Denis Smith ${ }^{\mathrm{a}}$ and Alan Irwin ${ }^{\mathrm{b}}$

${ }^{a}$ Department of Business and Management, University of Glasgow, UK ${ }^{b}$ Faculty of Social and Environmental Studies, University of Liverpool, UK 